\title{
Contact Toxicity and Repellency of the Essential Oil from Bupleurum bicaule Helm against Two Stored Product Insects
}

\author{
Xiao-Meng Wei, ${ }^{1}$ Shan-Shan Guo, ${ }^{2}$ Hua Yan, ${ }^{3}$ Xian-Long Cheng ${ }^{(D)},{ }^{3}$ \\ Feng Wei $\mathbb{1},^{1,3}$ and Shu-Shan Du $\mathbb{1}^{2}$ \\ ${ }^{1}$ Faculty of Traditional Chinese Medicine, Beijing University of Chinese Medicine, Beijing 102488, China \\ ${ }^{2}$ Beijing Key Laboratory of Traditional Chinese Medicine Protection and Utilization, Faculty of Geographical Science, \\ Beijing Normal University, Beijing 100875, China \\ ${ }^{3}$ National Institutes for Food and Drug Control, China Food and Drug Administration, Beijing 100050, China
}

Correspondence should be addressed to Feng Wei; weifeng@nifdc.org.cn and Shu-Shan Du; dushushan@bnu.edu.cn

Received 11 December 2017; Revised 2 February 2018; Accepted 27 February 2018; Published 16 April 2018

Academic Editor: Jose A. Pereira

Copyright (c) 2018 Xiao-Meng Wei et al. This is an open access article distributed under the Creative Commons Attribution License, which permits unrestricted use, distribution, and reproduction in any medium, provided the original work is properly cited.

\begin{abstract}
Essential oils obtained from many plants showed various kinds of insecticidal properties; some of them have been considered as alternative insecticides for pest control. The present study was aimed at determining the chemical composition of the essential oil from the roots of Bupleurum bicaule Helm, as well as evaluating the contact and repellent activities of the oil and four identified compounds against Lasioderma serricorne and Liposcelis bostrychophila adults. The essential oil was extracted by hydrodistillation, and its components were analyzed by gas chromatography-mass spectrometry (GC-MS). 26 components were determined and the main compounds included trans-2-isopropylbicyclo[4.3.0]non-3-en-8-one (25.9\%), 4,5-dimethyl$1,2,3,6,7,8,8 \mathrm{a}, 8 \mathrm{~b}$-octahydrobiphenylene (23.5\%), and 1,4-dimethoxy-2-tert-butylbenzene (4.3\%). It was found that the essential oil exhibited contact toxicity against $L$. serricorne $\left(\mathrm{LD}_{50}=11.91 \mu \mathrm{g} / \mathrm{adult}\right)$, but the contact toxicity against $L$. bostrychophila could not be observed. The essential oil also showed strong repellent activity against L. serricorne with percent repellency of $100 \%$ at $78.63 \mathrm{nl} / \mathrm{cm}^{2}$. Four chemical compounds, 1,4-dimethoxy-2-tert-butylbenzene, bornyl acetate, (2E,4E)-2,4-nonadienal, and $\beta$ bisabolene, exhibited various levels of bioactivities. The experimental results indicated that the essential oil of $B$. bicaule and its individual compounds could be used in insecticidal and repellent strategies for stored product insects.
\end{abstract}

\section{Introduction}

The economy of agriculture and food industry has been threatened by insects in the process of production, transportation, and storage. It is estimated that about $10-40 \%$ of the world's annual stored product loss was caused by the insects [1]. The cigarette beetle (Lasioderma serricorne Fabricius) and the booklouse (Liposcelis bostrychophila Badonnel) are two major insects in the warehouses of stored foods, grains, and some herbal medicines [2,3]. Under appropriate environmental conditions, they can reproduce rapidly [4, 5]. The insects not only consume the stored commodities, but also lead to contamination and deterioration of stored products in the short term. A great effort has been focused on the prophylaxis of insects in stored products. Many methods, such as the cold storage, the light traps, and the chemical treatment [5] have been successively used to control the insects. Among them the chemical treatment is the most commonly used method with different chemical synthetic insecticides. However, a series of negative effects such as insecticide residues and environmental damage have been exposed, so that the development of the new environmental friendly, economical, and effective methods $[2,6]$ is necessary. Antagonistic storage, a traditional method, has been used for Chinese medicinal material conservation for a long history. Our ancestors skillfully used the special odors of some Chinese herbs to repel the insects and to achieve the purpose of protecting another kind of medicinal materials [7]. For instance, Rhizoma Alismatis is easily infected by insects. If it is stored with Cortex Moutan which has a special odor, Rhizoma Alismatis would not be susceptible to insects, and the quality of the two medicinal materials would be 
maintained for a long time [8]. The antagonistic storage method is mostly related to the special odor reeked off by the stored materials. Thus, the essential oils of the stored materials could be considered as the effective elements in antagonistic storage method. The research on the essential oils would be helpful to reveal the mechanism of the antagonistic storage method. In practice, this kind of research has become a hot topic in the field of controlling stored product insects [9-11].

Bupleurum bicaule Helm (Chinese name: Zhuiye Chaihu) is widely distributed in northeast region of China, and its roots have been medicinally used for the treatment of fever, cold, hypochondriac pain, hepatitis, biliary tract infection, irregular menstruation, uterine prolapse, and anal prolapse [12-15]. As is well known, essential oils are abundant in Umbelliferae (Apiaceae) plants [16]. Many of these essential oils obtained from Umbelliferae (Apiaceae) plants have been proven to possess insecticidal activities against certain kinds of insects. For examples, the essential oil of Heracleum persicum showed fumigant toxicity against Callosobruchus maculatus [17], Pimpinella anisum essential oil also showed strong fumigant toxicity against Ephestia kuehniella and Sitophilus oryzae [18], and Ferula asafetida essential oil possessed strong repellent activity against Tribolium castaneum [19].

The phytochemistry of Bupleurum plants has been investigated, and some of the secondary metabolites obtained from B. salicifolium showed antifeedant activity against Spodoptera littoralis [20]. For B. bicaule, the chemical components of the essential oil obtained from this plant have been reported [21]. In this work, the essential oil of $B$. bicaule was further investigated, and its insecticidal and repellent activities against the cigarette beetles and booklice adults were evaluated; meanwhile, the same kinds of biological activity tests were carried out with four representative compounds identified in the sample of the essential oil.

\section{Materials and Methods}

2.1. Plant Materials and Preparation of the Essential Oil. Roots of $B$. bicaule were collected in Hailar, Inner Mongolia Autonomous Region, China (northern latitude: $9^{\circ} 5^{\prime}-19^{\circ} 27^{\prime}$; east longitude: $119^{\circ} 30^{\prime}-120^{\circ} 35^{\prime}$ ) in August 2016. The species was identified by Dr. Yan H. (National Institutes for Food and Drug Control, China Food and Drug Administration, China). The voucher specimen (NIFDC-20160801-01) was deposited at Herbarium (NIFDC) of National Institutes for Food and Drug Control. After air drying for one week $\left(25-28^{\circ} \mathrm{C}\right.$ and $\left.13-20 \% \mathrm{RH}\right)$, the dried roots $(2.4 \mathrm{~kg})$ were ground to powders with a grinding mill. The extraction of essential oil was carried out by hydrodistillation using a modified Clevenger apparatus for $8 \mathrm{~h}$ [22]. The distilled oils were dried over anhydrous sodium sulfate and stored in glass vials at $4^{\circ} \mathrm{C}$.

2.2. GC-MS and GC-FID Analysis. The GC-MS analysis of B. bicaule essential oil was performed by an Agilent $6890 \mathrm{~N}$ GC/MS instrument equipped with an Agilent $5973 \mathrm{~N}$ mass selective detector and a HP-5 MS column $(30 \mathrm{~m} \times 0.25 \mathrm{~mm}$ $\times 0.25 \mu \mathrm{m})$. The carrier gas was helium, and the flow rate was $1.0 \mathrm{~mL} / \mathrm{min}$. Analytical conditions are as follows: column temperature was programmed from $50^{\circ} \mathrm{C}(2 \mathrm{~min})$ to $150^{\circ} \mathrm{C}$ at $2^{\circ} \mathrm{C} / \mathrm{min}$ and kept isothermal for $2 \mathrm{~min}$, then increased to $250^{\circ} \mathrm{C}$ at $10^{\circ} \mathrm{C} / \mathrm{min}$, and held for $5 \mathrm{~min}$. The injector temperature was $250^{\circ} \mathrm{C}$. The MS spectra were obtained in the electron-impact mode with ionization energy of $70 \mathrm{eV}$, and mass range was from $m / z 50$ to 550 .

The essential oil was diluted with $n$-hexane to prepare a GC sample solution with content of $1 \%(\mathrm{v} / \mathrm{v})$, and the sample solution of $0.1 \mu \mathrm{L}$ was injected into the instrument. Relative percentages of the individual components were determined by GC-FID via percentage peak area calculations. These components were further identified based on their retention index and by comparison with NIST 05 (Standard Reference Data, Gaithersburg, MD) and Wiley 275 GC-MS databases (Wiley, New York, NY).

2.3. Test Insects. The cigarette beetles were originally delivered from Henan University of Technology, China, since 2013, and the species was identified by Dr. Lv J. H. (School of Food Science and Technology, Henan University of Technology, China). The booklice were adopted from China Agricultural University and identified by Dr. Liu Z. L. (China Agricultural University, China). The cigarette beetles were reared on wheat flour mixed with yeast $(10: 1, \mathrm{w} / \mathrm{w})$ at $12-13 \%$ moisture content, and the booklice were cultured with the flour mixture, which was prepared with flour, yeast, and milk powder at 10:1:1 mixed proportion [2]. Insect rearing were carried out in the dark in incubators at $29-30^{\circ} \mathrm{C}$ and $70-80 \% \mathrm{RH}$. All the unsexed insects used in the experiments were one to two weeks old. The escape proof was made of polytetrafluoroethylene (Beijing Sino-Rich Co., Ltd., Beijing, China) coating on all insect containers and experimental Petri dishes.

\subsection{Bioactivities}

2.4.1. Preparation of the Treatment Solutions. The essential oil and four representative compounds found in the oil were selected for bioactivity assays. The chemical compounds (2E,4E)-2,4-nonadienal and $\beta$-bisabolene were purchased from TCI (Shanghai) Development Co., Ltd. (Shanghai, China). 1,4-Dimethoxy-2-tert-butylbenzene was obtained from JW\&Y PharmLab (Shanghai), PharmLab Co., Ltd. (Shanghai, China). Bornyl acetate was purchased from Acros Organics Co., Ltd. (Geel, Belgium). N,N-Diethyl-3methylbenzamide (DEET) was obtained from the National Center of Pesticide Standards (8 Shenliao West Road, Tiexi District, Shenyang, China). Each of the above samples was dissolved in the solvent of $n$-hexane, and their stock solutions with the known concentrations were prepared.

2.4.2. Contact Toxicity. In the evaluation of contact toxicity, two kinds of experimental methods were used based on the size of the insects. The contact toxicity against cigarette beetles was carried out with the methods described in the literature [23]. Before the formal test, the appropriate concentration range was determined by preliminary tests. Ultimately, the essential oil and four selected compounds 
were diluted with $n$-hexane into five concentrations. Drop $0.5 \mu \mathrm{L}$ dilutions on the dorsal thorax of each insect using a TopPette $(0.5-10 \mu \mathrm{L}$, Dragon Laboratory Instruments Co., Ltd., Beijing, China). Ten insects were used for each concentration, and the experiment was replicated five times for each concentration. Then the treated and control insects were transferred to glass vials $(2.5 \mathrm{~cm}$ in diameter, $5.5 \mathrm{~cm}$ in height). After being cultured in an incubator $\left(29-30^{\circ} \mathrm{C}\right.$ and $70-80 \%$ R.H) for $24 \mathrm{~h}$, the mortality of tested insects was observed and recorded, and the $\mathrm{LD}_{50}$ values were calculated by Probit analysis (SPSS 20.0) [24].

For booklice, the contact toxicity was tested as described [25]. A filter paper of $5.5 \mathrm{~cm}$ in diameter was treated with $300 \mu \mathrm{L}$ dilutions of each test concentration. The treated filter paper was fixed in a 5.5-cm-diameter Petri dish with solid glue, and 10 test insects were placed in each Petri dish. Five concentrations (in $n$-hexane) and five replicates of each concentration were used. In the above experiments, $n$ hexane was used as a negative control. The chemical synthetic insecticide pyrethrins was usually served as a positive control; its mortality was taken from Yang et al's data with the same experimental methods [26]. The mortality of insects was recorded after these covered-Petri dishes were placed in an incubator at $29-30^{\circ} \mathrm{C}$ and $70-80 \% \mathrm{RH}$ for $24 \mathrm{~h}$. The mortality data was corrected by Abbott's formula [27]:

$$
\operatorname{corrected} \text { mortality }(\%)=100 \times \frac{\left(M_{c}-M_{t}\right)}{\left(1-M_{c}\right)},
$$

where $M_{t}$ is the observed mortality and $M_{c}$ is the control mortality. With these data, the $\mathrm{LD}_{50}$ values were calculated by Probit analysis (SPSS 20.0).

\subsubsection{Repellent Activity. The repellent activity of $B$. bicaule} essential oil and four components against cigarette beetles and booklice was investigated with the method proposed by Zhang et al. [28]. The experiments were set with five concentrations (cigarette beetles: 78.63, 15.73, 3.15, 0.63, and $0.13 \mathrm{~nL} / \mathrm{cm}^{2}$; booklice: $63.17,12.63,2.53,0.51$, and $0.10 \mathrm{~nL} / \mathrm{cm}^{2}$ ) and two observation times $(2 \mathrm{~h}$ and $4 \mathrm{~h})$. For cigarette beetles, the essential oil and four selected compounds were diluted with $n$-hexane. Filter paper ( $9 \mathrm{~cm}$ in diameter) was symmetrically cut into two pieces, and $500 \mu \mathrm{L}$ dilution of each concentration was dropped evenly on half of the filter paper, while the other half was treated with $500 \mu \mathrm{L}$ of $n$ hexane as a negative control. After being air-dried for $30 \mathrm{~s}$, both two pieces were stuck to the bottom of the Petri dish ( $9 \mathrm{~cm}$ in diameter) with solid glue abreast. For booklice, due to its tiny body, the diameters of the Petri dish and filter paper were reduced to $5.5 \mathrm{~cm}$. Filter paper was cut into two pieces, and one piece was treated with $150 \mu \mathrm{L}$ of each solution separately. The other half (negative control) was treated with the same volume of $n$-hexane. For each test, 20 insects were placed at the center of the disk and covered quickly with lids. All the above procedures were repeated five times for each concentration, and each experiment was repeated three times.

As a commercial insect repellant, DEET was served as positive control. Counts of insects on each half of the paper were recorded separately. The percent repellency $(\mathrm{PR})$ of each test was calculated by the following formula [23]:

$$
\operatorname{PR}(\%)=\left[\frac{\left(N_{c}-N_{t}\right)}{\left(N_{c}+N_{t}\right)}\right] \times 100,
$$

where $N_{c}$ is the number of insects in the negative control half and $N_{t}$ is the number of insects in the tested half. The percent repellency was transformed to arcsine square root values for analysis of variance (ANOVA), and the effect on the transformed arcsine of the percent repellency of different treatments (the essential oil, the four compounds, and the control) at each concentration and exposure time was analyzed separately. Significant differences in repellence rates among treatments were given by the analysis of Tukey's test (SPSS 20.0 for Windows 2007).

\section{Results and Discussion}

3.1. Chemical Constituents of the Essential Oil. The yellow essential oil was obtained from B. bicaule with a yield of $0.04 \%$ $(v / w)$. Its chemical components were analyzed by the GCMS. 26 compounds were identified and their relative contents in the oil sample were determined. The total amount of all the identified compounds was $85.5 \%(\mathrm{w} / \mathrm{w})$ of the essential oil. The content of trans-2-isopropylbicyclo[4.3.0]non3 -en-8-one was $25.9 \%$, and the content of 4,5-dimethyl$1,2,3,6,7,8,8 \mathrm{a}, 8 \mathrm{~b}$-octahydrobiphenylene was $23.5 \%$. These two compounds could be considered as the major components of the essential oil. The results are summarized in Table 1.

With the further analysis of the GS-MS results, it was found that the essential oil contained a plenty of monoterpenes and sesquiterpenes, and their contents accounted for $27.0 \%$ and $21.3 \%$ of the essential oil, respectively. The other types of chemical components included aldehydes, alkynes, and aromatic compounds. In a published paper [21], Xu and his partners reported that 19 compounds were identified in the root oil of $B$. bicaule collected from Inner Mongolia, China, and all the types of chemical components mentioned above also existed in $\mathrm{Xu}$ et al.s oil sample. The five types of components accounted for about $60 \%$ of the essential oils in the two works. However, the significant difference between the results presented in Xu's paper and our results could be figured out. The compound with the highest content predicted in Xu's paper was 4-tridecen-6-yne (42.6\%), but only its isomer, 6-tridecen-4-yne, was discovered in our sample and its content only accounted for $2.7 \%$ of the essential oil. The highest content compound in our sample was trans-2-isopropylbicyclo[4.3.0] non-3-en-8-one (25.9\%), and it was not reported in the literature.

The other differences were showed in Figure 1, the content of aldehydes $(12.6 \%)$ in Xu's paper was higher than that of terpenoids (6.2\%), and the monoterpenes only accounted for a minor proportion $(0.8 \%)$. However, in our case, the content of terpenoids was $48.3 \%$ (27.0\% for monoterpenes and $21.3 \%$ for sesquiterpenes), which was much higher than that of aldehyde compounds (4.8\%). The above differences might be caused by many variables such as the growth environment 
TABLE 1: Chemical composition of the essential oil of Bupleurum bicaule.

\begin{tabular}{|c|c|c|c|c|}
\hline Compounds & Relative content (\%) & ${ }^{\mathrm{a}} \mathrm{RI}_{\exp }$ & ${ }^{\mathrm{b}} \mathrm{RI}_{\text {lit }}$ & Identification methods ${ }^{c}$ \\
\hline \multicolumn{5}{|l|}{ Aldehydes } \\
\hline$(2 \mathrm{E}, 4 \mathrm{E})-2,4-$ Octadienal & 0.8 & 1113 & 1109 & MS; RI \\
\hline$(2 \mathrm{E}, 4 \mathrm{E})-2,4-$ Nonadienal & 1.2 & 1214 & 1217 & MS; RI \\
\hline (2E,4E)-2,4-Decadienal & 2.8 & 1317 & 1316 & MS; RI \\
\hline \multicolumn{5}{|l|}{ Monoterpenes } \\
\hline Bornyl acetate & 1.1 & 1280 & 1281 & MS; RI \\
\hline Trans-2-isopropylbicyclo[4.3.0]non-3-en-8-one & 25.9 & 1765 & 1765 & MS; RI \\
\hline \multicolumn{5}{|l|}{ Sesquiterpenes } \\
\hline$\alpha$-Longipinene & 0.5 & 1352 & 1351 & MS; RI \\
\hline$\beta$-Elemene & 0.8 & 1391 & 1393 & MS; RI \\
\hline$\beta$-Cuvebene & 1.5 & 1390 & 1388 & MS; RI \\
\hline 1,4,7,-Cycloundecatriene, 1,5,9,9-tetramethyl-, Z,Z,Z- & 1.9 & 1456 & 1454 & MS; RI \\
\hline Calarene & 2.1 & 1467 & 1463 & MS; RI \\
\hline$\gamma$-Gurjunene & 2.0 & 1479 & 1472 & MS; RI \\
\hline$(\mathrm{E}, \mathrm{E})-\alpha$-Farnesene & 0.4 & 1505 & 1505 & MS; RI \\
\hline$\beta$-Bisabolene & 2.7 & 1510 & 1511 & MS; RI \\
\hline Cuparene & 2.9 & 1502 & 1499 & MS; RI \\
\hline (E)-Nerolidol & 0.5 & 1565 & 1564 & MS; RI \\
\hline Spathulenol & 0.9 & 1582 & 1578 & MS; RI \\
\hline Caryophyllene oxide & 1.4 & 1583 & 1580 & MS; RI \\
\hline Humulene oxide II & 1.4 & 1607 & 1611 & MS; RI \\
\hline$\alpha$-Cadinol & 1.4 & 1653 & 1654 & MS; RI \\
\hline$\tau$-Muurolol & 0.6 & 1662 & 1660 & MS; RI \\
\hline Juniper camphor & 0.3 & 1690 & 1693 & MS; RI \\
\hline \multicolumn{5}{|l|}{ Alkynes } \\
\hline (6Z)-6-Tridecen-4-yne & 2.7 & 1470 & 1470 & MS; RI \\
\hline \multicolumn{5}{|l|}{ Aromatic compounds } \\
\hline 1,4-Dimethoxy-2-tert-butylbenzene & 4.3 & 1477 & 1477 & MS; RI \\
\hline Myristicin & 1.6 & 1529 & 1523 & MS; RI \\
\hline $\begin{array}{l}\text { 2(1H)Naphthalenone,3,5,6,7,8,8a-hexahydro-4,8a- } \\
\text { dimethyl-6-(1-methylethenyl)- }\end{array}$ & 0.3 & 1772 & 1773 & MS; RI \\
\hline \multicolumn{5}{|l|}{ Others } \\
\hline 4,5-Dimethyl-1,2,3,6,7,8,8a,8b-octahydrobiphenylene & 23.5 & 1357 & 1357 & MS; RI \\
\hline
\end{tabular}

${ }^{a}$ Retention index (RI) in this experiment relative to the homologous series of n-alkanes $\left(\mathrm{C}_{5}-\mathrm{C}_{36}\right)$ on the HP-5 MS capillary column. ${ }^{\mathrm{b}} \mathrm{RI}$ in literature. ${ }^{\mathrm{c}} \mathrm{Mass}$ spectrum.

of plants, the harvest time, and treatment of samples. These differences might further affect the biological activities.

It was reported that terpenoids and aromatic compounds exhibited excellent bioactivities against different stored product insect pests [29-32] and aldehydes showed fair contact toxicity and repellent activities [33]. Here, four representative compounds were selected from 26 components identified in our sample as they belong to the chemical types of monoterpenes, sesquiterpenes, aldehydes, or aromatic compounds, respectively. Their bioactivity tests were evaluated as well. They are bornyl acetate, $\beta$-bisabolene, $(2 \mathrm{E}, 4 \mathrm{E})-$ 2,4-nonadienal, and 1,4-dimethoxy-2-tert-butylbenzene. The molecular structures of the four selected compounds are shown in Figure 2.

3.2. Contact Toxicity. The results of contact toxicity of the essential oil and selected compounds against cigarette beetles and booklice are listed in Table 2. The results showed that the essential oil exhibited fair contact toxicity against cigarette beetles with a $\mathrm{LD}_{50}$ value of $11.91 \mu \mathrm{g} / \mathrm{adult}$ but expressed unobservable toxicity against booklice in our measure range.

Among the four selected compounds, (2E,4E)-2,4-nonadienal showed the strongest toxicity against cigarette beetles $\left(\mathrm{LD}_{50}=2.31 \mu \mathrm{g} / \mathrm{adult}\right)$ and booklice $\left(\mathrm{LD}_{50}=32.23 \mu \mathrm{g} / \mathrm{cm}^{2}\right)$. 


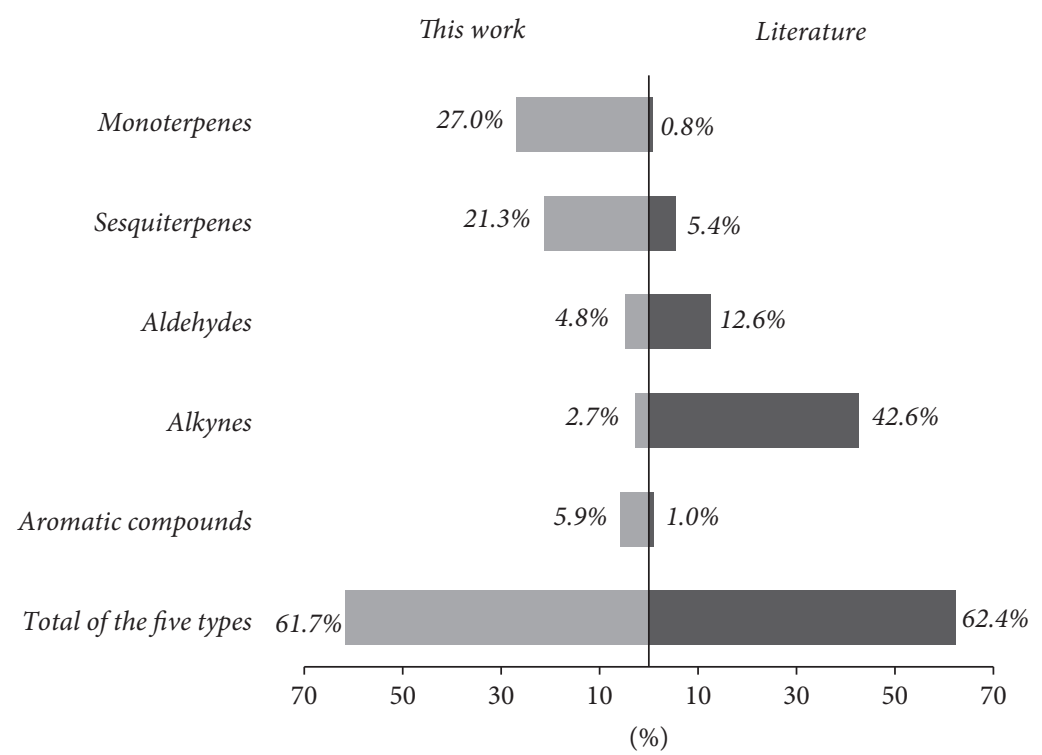

FIGURE 1: Percentage of different types of compounds in essential oils of this work and literature.

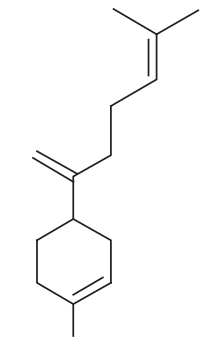

$\beta$-Bisabolene<smiles>COc1ccc(OC)c(C(C)(C)C)c1</smiles>

1,4-Dimethoxy-2-tert-butylbenzene

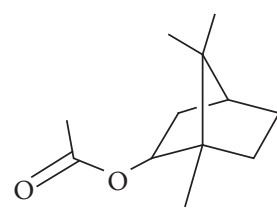

Bornyl acetate

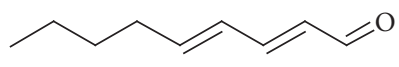

(2E,4E)-2,4-Nonadienal

Figure 2: Molecular structures of selected compounds from the essential oil of Bupleurum bicaule.

TABLE 2: Contact toxicity of Bupleurum bicaule essential oil and its constituents against Lasioderma serricorne (LS) and Liposcelis bostrychophila (LB) adults.

\begin{tabular}{|c|c|c|c|c|c|c|}
\hline Insects & Treatments & Concentrations (\%) & $\begin{array}{c}\mathrm{LD}_{50} \\
(\mu \mathrm{g} / \text { adult }) /\left(\mu \mathrm{g} / \mathrm{cm}^{2}\right)\end{array}$ & $\begin{array}{c}95 \% \mathrm{FL} \\
(\mu \mathrm{g} / \text { adult }) /\left(\mu \mathrm{g} / \mathrm{cm}^{2}\right)\end{array}$ & Slope \pm SE & $\begin{array}{c}\text { Chi square } \\
\left(\chi^{2}\right)\end{array}$ \\
\hline \multirow{6}{*}{ LS } & Essential oil & $1.91-10.00$ & 11.91 & $7.04-15.66$ & $2.01 \pm 0.39$ & 17.50 \\
\hline & $\beta$-Bisabolene & $2.97-15.00$ & 24.99 & $21.68-29.14$ & $3.86 \pm 0.56$ & 3.61 \\
\hline & 1,4-Dimethoxy-2-tert-butylbenzene & $1.97-10.00$ & 23.56 & $20.03-27.24$ & $3.18 \pm 0.55$ & 2.90 \\
\hline & Bornyl acetate & $0.90-4.40$ & 9.42 & $8.14-10.87$ & $0.98 \pm 0.17$ & 7.53 \\
\hline & $(2 \mathrm{E}, 4 \mathrm{E})-2,4-$ Nonadienal & $0.27-1.30$ & 2.31 & $2.03-2.61$ & $4.00 \pm 0.62$ & 9.44 \\
\hline & Pyrethrins $^{\mathrm{a}}$ & -- & 0.24 & $0.22-0.30$ & $3.34 \pm 0.32$ & 13.11 \\
\hline \multirow{6}{*}{ LB } & Essential oil & $0-5.00$ & -- & -- & -- & -- \\
\hline & $\beta$-Bisabolene & $0-50.00$ & -- & -- & -- & -- \\
\hline & 1,4-Dimethoxy-2-tert-butylbenzene & $0.12-1.00$ & 62.34 & $55.97-69.66$ & $6.42 \pm 0.87$ & 3.93 \\
\hline & Bornyl acetate & $0.20-0.40$ & 36.67 & $34.67-38.55$ & $16.73 \pm 2.28$ & 7.04 \\
\hline & $(2 \mathrm{E}, 4 \mathrm{E})-2,4-$ Nonadienal & $0.20-0.40$ & 32.23 & $30.59-33.97$ & $17.08 \pm 2.31$ & 9.66 \\
\hline & Pyrethrins $^{\mathrm{a}}$ & -- & 18.72 & $17.60-19.92$ & $2.98 \pm 0.40$ & 10.56 \\
\hline
\end{tabular}

${ }^{a}$ Data from Yang et al. [26]. 
TABLE 3: Percent repellency (PR) of the essential oil from Bupleurum bicaule and its constituents against Lasioderma serricorne adults at $2 \mathrm{~h}$ and $4 \mathrm{~h}$ after exposure. ${ }^{*}$ Comparison of different samples at the same concentration, $\mathrm{df}=5$.

\begin{tabular}{|c|c|c|c|c|c|c|}
\hline \multirow{2}{*}{ Times } & \multirow{2}{*}{ Treatments } & \multicolumn{5}{|c|}{ Concentrations $\left(\mathrm{nL} / \mathrm{cm}^{2}\right)$} \\
\hline & & 78.63 & 15.73 & 3.15 & 0.63 & 0.13 \\
\hline \multirow{8}{*}{$2 \mathrm{~h}$} & Essential oil & $100 \pm 0^{c}$ & $74 \pm 12^{c}$ & $70 \pm 12^{c}$ & $66 \pm 11^{\mathrm{b}}$ & $38 \pm 4^{\mathrm{bc}}$ \\
\hline & $\beta$-Bisabolene & $90 \pm 6^{\mathrm{bc}}$ & $12 \pm 9^{b}$ & $34 \pm 15^{\mathrm{bc}}$ & $10 \pm 16^{\mathrm{a}}$ & $56 \pm 12^{\mathrm{c}}$ \\
\hline & 1,4-Dimethoxy-2-tert-butylbenzene & $62 \pm 11^{\mathrm{a}}$ & $40 \pm 13^{\mathrm{bc}}$ & $34 \pm 15^{\mathrm{bc}}$ & $6 \pm 12^{\mathrm{a}}$ & $14 \pm 12^{\mathrm{b}}$ \\
\hline & Bornyl acetate & $74 \pm 12^{\mathrm{ab}}$ & $-28 \pm 19^{\mathrm{a}}$ & $-4 \pm 17^{\mathrm{a}}$ & $-4 \pm 9^{\mathrm{a}}$ & $-36 \pm 17$ \\
\hline & $(2 \mathrm{E}, 4 \mathrm{E})-2,4-$ Nonadienal & $56 \pm 12^{\mathrm{a}}$ & $66 \pm 20^{c}$ & $4 \pm 19^{\mathrm{ab}}$ & $16 \pm 17^{\mathrm{ab}}$ & $60 \pm 10^{\mathrm{c}}$ \\
\hline & DEET & $88 \pm 7^{b}$ & $76 \pm 14$ & $28 \pm 7^{\mathrm{bc}}$ & $20 \pm 14^{\mathrm{ab}}$ & $16 \pm 7^{\mathrm{b}}$ \\
\hline & $F$ & 15.878 & 20.895 & 9.823 & 5.244 & 39.261 \\
\hline & $P$ & 0 & 0 & 0 & 0.002 & 0 \\
\hline \multirow{8}{*}{$4 \mathrm{~h}$} & Essential oil & $100 \pm 0^{\mathrm{c}}$ & $62 \pm 15^{\mathrm{bcd}}$ & $24 \pm 19^{\mathrm{ab}}$ & $28 \pm 19^{\mathrm{bc}}$ & $12 \pm 18^{\mathrm{b}}$ \\
\hline & $\beta$-Bisabolene & $88 \pm 12^{\mathrm{bc}}$ & $26 \pm 17^{\mathrm{b}}$ & $24 \pm 11^{\mathrm{ab}}$ & $14 \pm 17^{\mathrm{abc}}$ & $34 \pm 18^{\mathrm{bc}}$ \\
\hline & 1,4-Dimethoxy-2-tert-butylbenzene & $46 \pm 20^{\mathrm{a}}$ & $32 \pm 9^{b c}$ & $34 \pm 17^{\mathrm{ab}}$ & $-4 \pm 16^{\mathrm{ab}}$ & $28 \pm 4^{\mathrm{bc}}$ \\
\hline & Bornyl acetate & $68 \pm 13^{\mathrm{ab}}$ & $-4 \pm 12^{\mathrm{a}}$ & $14 \pm 12^{\mathrm{ab}}$ & $-8 \pm 18^{\mathrm{ab}}$ & $-18 \pm 11^{\mathrm{a}}$ \\
\hline & $(2 \mathrm{E}, 4 \mathrm{E})-2,4-$ Nonadienal & $50 \pm 19^{\mathrm{a}}$ & $72 \pm 9^{\mathrm{cd}}$ & $12 \pm 18^{\mathrm{a}}$ & $-14 \pm 16^{\mathrm{a}}$ & $32 \pm 19^{\mathrm{bc}}$ \\
\hline & DEET & $98 \pm 2^{c}$ & $78 \pm 9^{d}$ & $58 \pm 16^{\mathrm{b}}$ & $56 \pm 14^{\mathrm{c}}$ & $46 \pm 7^{\mathrm{c}}$ \\
\hline & $F$ & 15.428 & 17.091 & 2.713 & 5.753 & 13.079 \\
\hline & $P$ & 0 & 0 & 0.044 & 0.001 & 0 \\
\hline
\end{tabular}

${ }^{*}$ Different letters in the same column $(2 \mathrm{~h}$ and $4 \mathrm{~h}$, resp. $)$ mean significant differences $(P<0.05)$ in ANOVA and Tukey's tests. PR was subjected to an arcsine square-root transformation before analysis.

Bornyl acetate also showed certain toxicity against the two insects $\left(\mathrm{LD}_{50}=9.42 \mu \mathrm{g} /\right.$ adult and $36.67 \mu \mathrm{g} / \mathrm{cm}^{2}$, resp. $)$, while the toxicity of 1,4-dimethoxy-2-tert-butylbenzene and $\beta$ bisabolene was relatively weak. No toxicity against booklice was observed for $\beta$-bisabolene under the testing concentrations.

From the results, it could be calculated that the contact toxicity of (2E,4E)-2,4-nonadienal against booklice was only 1.7 times less than that of pyrethrins $\left(\mathrm{LD}_{50}=18.72 \mu \mathrm{g} / \mathrm{cm}^{2}\right)$. In You et al.s work [34], it was reported that the perilla aldehyde isolated from the essential oil of Purple Perilla aerial parts also showed significant contact toxicity against cigarette beetles $\left(\mathrm{LD}_{50}=3.82 \mu \mathrm{g} / \mathrm{adult}\right)$. By the structural analysis, it was found that both of $(2 \mathrm{E}, 4 \mathrm{E})-2,4$-nonadienal and perilla aldehyde have aldehyde fragment. The toxic characteristic of these compounds against insects might be related to the presence of an aldehyde group in these compounds. Therefore, the content of (2E,4E)-2,4-nonadienal could be considered as one of the key elements which would affect the contact toxicity of the essential oil against certain kinds of insects.

3.3. Repellency. The results of the ANOVAs indicated that the repellent rate against both insects significantly differ with the different treatments. These results are given in Tables 3 and 4 .

The essential oil showed strong repellency against cigarette beetles. After $2 \mathrm{~h}$ of exposure, the percent repellency (PR) of the essential oil reached $100 \%$ at the highest concentration $\left(78.63 \mathrm{~nL} / \mathrm{cm}^{2}\right)$. The $\mathrm{PR}$ values continuously declined with the decrease of the tested concentrations. The repellent characteristics of the four compounds against the cigarette beetles were variable. At the dose of $78.63 \mathrm{~nL} / \mathrm{cm}^{2}$, all the four compounds showed definite repellent activities against cigarette beetles, although their individual efficiency of repellency was not as good as that of the essential oil treatment. The PR values of $\beta$-bisabolene, 1,4-dimethoxy-2-tertbutylbenzene, bornyl acetate, and (2E,4E)-2,4-nonadienal were $90 \%, 62 \%, 74 \%$, and $56 \%$, respectively, after $2 \mathrm{~h}$ of exposure. However, the repellent characteristics of the four compounds were obviously different at lower concentrations. The experimental data were further analyzed by Tukey' test, and the statistical results (see Table 3 ) could be used to exam the repellency level of each sample. Testing results of $0.13 \mathrm{~nL} / \mathrm{cm}^{2}$ showed that $\beta$-bisabolene and $(2 \mathrm{E}, 4 \mathrm{E})-2,4-$ nonadienal possessed a higher level of repellency than DEET $(P=0.019$ and 0.009 , resp. $)$ after $2 \mathrm{~h}$ of exposure. The repellency of 1,4-dimethoxy-2-tert-butylbenzene was comparable to DEET $(P=0.966)$, while the bornyl acetate showed an insect attractant property.

As the results show in Table 4, the B. bicaule essential oil showed relatively weak repellency against booklice; the highest repellent rate of the essential oil was only $56 \%$ relative to $\operatorname{DEET}(\mathrm{PR}=98 \%)$ at the dose of $12.63 \mathrm{~nL} / \mathrm{cm}^{2}$ after $2 \mathrm{~h}$ of exposure. However, some of individual compounds showed certain repellent activities. At low concentration $\left(0.10 \mathrm{~nL} / \mathrm{cm}^{2}\right)$, the repellency of the four compounds was at the same level as that of DEET $(P=0.952,0.855,1.000$, and 1.000 , resp.) after $2 \mathrm{~h}$ of exposure. At the highest concentration $\left(63.17 \mathrm{~nL} / \mathrm{cm}^{2}\right)$, only $\beta$-bisabolene showed an obvious repellent activity with $P R$ value of $76 \%$ after $2 \mathrm{~h}$ of exposure.

The experimental results and data analysis showed that the repellent rates of the essential oil were almost comparable to those of the positive control at all testing concentrations against cigarette beetles. Each of the four compounds exhibited a different level of the repellent activity against 
TABLe 4: Percent repellency (PR) of the essential oil from Bupleurum bicaule and its constituents against Liposcelis bostrychophila adults at $2 \mathrm{~h}$ and $4 \mathrm{~h}$ after exposure. ${ }^{*}$ Comparison of different samples at the same concentration, $\mathrm{df}=5$.

\begin{tabular}{|c|c|c|c|c|c|c|}
\hline \multirow{2}{*}{ Times } & \multirow{2}{*}{ Treatments } & \multicolumn{5}{|c|}{ Concentrations $\left(\mathrm{nL} / \mathrm{cm}^{2}\right)$} \\
\hline & & 63.17 & 12.63 & 2.53 & 0.51 & 0.10 \\
\hline \multirow{8}{*}{$2 \mathrm{~h}$} & Essential oil & $50 \pm 12^{\mathrm{ab}}$ & $56 \pm 12^{\mathrm{bc}}$ & $4 \pm 17^{\mathrm{a}}$ & $24 \pm 19^{\mathrm{a}}$ & $-6 \pm 20^{\mathrm{a}}$ \\
\hline & $\beta$-Bisabolene & $76 \pm 15^{\mathrm{bc}}$ & $74 \pm 15^{\mathrm{cd}}$ & $42 \pm 19^{\mathrm{ab}}$ & $12 \pm 18^{\mathrm{a}}$ & $18 \pm 16^{\mathrm{a}}$ \\
\hline & 1,4-Dimethoxy-2-tert-butylbenzene & $52 \pm 19^{\mathrm{ab}}$ & $8 \pm 19^{\mathrm{a}}$ & $36 \pm 13^{\mathrm{ab}}$ & $22 \pm 18^{\mathrm{a}}$ & $16 \pm 13^{\mathrm{a}}$ \\
\hline & Bornyl acetate & $12 \pm 14^{\mathrm{a}}$ & $20 \pm 10^{\mathrm{ab}}$ & $32 \pm 9^{\mathrm{ab}}$ & $10 \pm 18^{\mathrm{a}}$ & $34 \pm 16^{\mathrm{a}}$ \\
\hline & $(2 \mathrm{E}, 4 \mathrm{E})-2,4-$ Nonadienal & $18 \pm 20^{\mathrm{a}}$ & $74 \pm 8^{\mathrm{cd}}$ & $24 \pm 18^{\mathrm{a}}$ & $20 \pm 10^{\mathrm{a}}$ & $28 \pm 14^{\mathrm{a}}$ \\
\hline & DEET & $100 \pm 0^{c}$ & $98 \pm 2^{\mathrm{d}}$ & $78 \pm 10^{\mathrm{b}}$ & $66 \pm 8^{\mathrm{a}}$ & $8 \pm 3^{\mathrm{a}}$ \\
\hline & $F$ & 8.980 & 12.170 & 5.299 & 1.998 & 2.173 \\
\hline & $P$ & 0 & 0 & 0.002 & 0.115 & 0.091 \\
\hline \multirow{8}{*}{$4 \mathrm{~h}$} & Essential oil & $44 \pm 13^{\mathrm{abc}}$ & $48 \pm 15^{\mathrm{a}}$ & $16 \pm 10^{\mathrm{b}}$ & $36 \pm 10^{\mathrm{a}}$ & $-10 \pm 16 a$ \\
\hline & $\beta$-Bisabolene & $74 \pm 22^{\mathrm{bc}}$ & $64 \pm 20^{\mathrm{a}}$ & $-16 \pm 15^{\mathrm{a}}$ & $48 \pm 20^{\mathrm{a}}$ & $16 \pm 18^{\mathrm{ab}}$ \\
\hline & 1,4-Dimethoxy-2-tert-butylbenzene & $20 \pm 15^{\mathrm{ab}}$ & $28 \pm 20^{\mathrm{a}}$ & $18 \pm 16^{\mathrm{b}}$ & $30 \pm 14^{\mathrm{a}}$ & $18 \pm 18^{\mathrm{ab}}$ \\
\hline & Bornyl acetate & $10 \pm 19^{\mathrm{a}}$ & $24 \pm 10^{\mathrm{a}}$ & $38 \pm 12^{\mathrm{bc}}$ & $22 \pm 18^{\mathrm{a}}$ & $44 \pm 18$ \\
\hline & $(2 \mathrm{E}, 4 \mathrm{E})-2,4$-Nonadienal & $28 \pm 8^{\mathrm{ab}}$ & $36 \pm 13^{\mathrm{a}}$ & $46 \pm 7^{\mathrm{bc}}$ & $14 \pm 3^{\mathrm{a}}$ & $8 \pm 20^{\mathrm{ab}}$ \\
\hline & DEET & $96 \pm 3^{c}$ & $82 \pm 5^{\mathrm{a}}$ & $68 \pm 3^{c}$ & $54 \pm 6^{\mathrm{a}}$ & $22 \pm 5^{\mathrm{ab}}$ \\
\hline & $F$ & 7.308 & 2.695 & 10.321 & 2.014 & 2.564 \\
\hline & $P$ & 0 & 0.045 & 0 & 0.113 & 0.054 \\
\hline
\end{tabular}

${ }^{*}$ Different letters in the same column $(2 \mathrm{~h}$ and $4 \mathrm{~h}$, resp. $)$ mean significant differences $(P<0.05)$ in ANOVA and Tukey's tests. PR was subjected to an arcsine square-root transformation before analysis.

cigarette beetles. Accordingly, it could be considered that these compounds would make various degrees of contribution to the strong repellency of the essential oil. Among them, $\beta$-bisabolene (a sesquiterpene) might be the most important one which majorly affected the repellent activity against cigarette beetles. It has been reported that the sesquiterpenes showed repellent activities against several insects. In Khani and Heydarian's work, the essential oil of Teucrium polium subsp. capitatum (L.), which was rich in sesquiterpene, showed $60 \%$ and $52 \%$ repellency against Teucrium castaneum and Callosobruchus maculatus adults [35]. Based on the above findings, it was believed that the essential oil of $B$. bicaule and the types of sesquiterpenes compounds would be the exploration direction of natural repellents.

\section{Conclusions}

In this work, the chemical composition of B. bicaule essential oil was determined, and its contact and repellent activities against two stored product insects were investigated along with four individual components. A compound (2E,4E)-2,4nonadienal with striking contact toxicity was found, and the essential oil showed considerable contact and repellent activities, which could be attributed to the existence of different chemical compounds in essential oil. Some of those components might be the material basis of active effect. This work would provide scientific basis for further development and utilization of B. bicaule in stored product insects control. There must be a certain relationship between the bioactivity and structure of the compounds, which deserves further study and discussion.

\section{Conflicts of Interest}

The authors declare that there are no conflicts of interest.

\section{Acknowledgments}

This project was supported by the National Natural Science Foundation of China (no. 81274025).

\section{References}

[1] T. Bhumi, C. Urvi, and P. Pragna, "Biopesticidal potential of some plant derived essential oils against the stored grain pests," International Journal of Zoological Investigations, vol. 3, pp. 188197, 2017.

[2] S.-S. Guo, W.-J. Zhang, C.-X. You et al., "Chemical composition of essential oil extracted from Laggera pterodonta and its bioactivities against two stored product insects," Journal of Food Processing and Preservation, vol. 41, no. 2, Article ID e12941, 2017.

[3] M. Hori, "Repellency of hinokitiol against the cigarette beetle, Lasioderma serricorne (Fabricius) (Coleoptera: Anobiidae)," Applied Entomology and Zoology, vol. 39, no. 3, pp. 521-526, 2004.

[4] B. D. Turner, "Liposcelis bostrychophila (psocoptera: Liposcelididae), a stored food pest in the UK," International Journal of Pest Management, vol. 40, no. 2, pp. 179-190, 1994.

[5] W.-J. Zhang, Z. Zhang, Z.-Y. Chen et al., "Chemical composition of essential oils from six Zanthoxylum species and their repellent activities against two stored-product insects," Journal of Chemistry, vol. 2017, Article ID 1287362, 2017.

[6] M. Lal, B. Ram, and P. Tiwari, "Botanicals to Cope Stored Grain Insect Pests: A Review," International Journal of Current 
Microbiology and Applied Sciences, vol. 6, no. 6, pp. 1583-1594, 2017.

[7] Q.-X. Han and J.-L. Chen, "Progress in antagonistic storage of Chinese traditional medicinal materials," Journal of Zhongkai Agrotechnical College, vol. 14, no. 3, pp. 59-63, 2001.

[8] Y.-L. Chang, L. Li, and Q.-N. Wu, "Study on storage and conservation technique of Rhizoma Alismatis," Research and Practice of Chinese Medicines, vol. 24, no. 4, pp. 70-73, 2010.

[9] H. R. El-Seedi, N. S. Khalil, M. Azeem et al., "Chemical composition and repellency of essential oils from four medicinal plants against Ixodes ricinus Nymphs (Acari: Ixodidae)," Journal of Medical Entomology, vol. 49, no. 5, pp. 1067-1075, 2012.

[10] M. Maedeh, I. Hamzeh, D. Hossein, A. Majid, and R. K. Reza, "Bioactivity of essential oil from Zingiber officinale (Zingiberaceae) against three stored-product insect species," Journal of Essential Oil Bearing Plants, vol. 15, no. 1, pp. 122-133, 2012.

[11] J.-Y. Liang, W.-T. Wang, Y.-F. Zheng et al., "Bioactivities and chemical constituents of essential oil extracted from Artemisia anethoides against two stored product insects," Journal of Oleo Science, vol. 66, no. 1, pp. 71-76, 2017.

[12] J. Q. Mao, Y. Zhang, J. Gu, X. Zhang, and L. Ma, "Comparative study on antipyretic effect of naphtha in Bupleurum chinense," Chinese Journal of Hospital Pharmacy, vol. 27, pp. 156-159, 2007.

[13] J. Zhu, C. Luo, P. Wang, Q. He, J. Zhou, and H. Peng, "Saikosaponin A mediates the inflammatory response by inhibiting the MAPK and NF- $\kappa$ B pathways in LPS-stimulated RAW 264.7 cells," Experimental and Therapeutic Medicine, vol. 5, no. 5, pp. 1345-1350, 2013.

[14] H. Zhao, S. Li, and H. Zhang, "Saikosaponin a protects against experimental sepsis via inhibition of NOD2-mediated NF- $\kappa \mathrm{B}$ activation," Experimental and Therapeutic Medicine, vol. 10, no. 2, pp. 823-827, 2015.

[15] T. Konno, K. Ninomiya, M. Yoshikawa, H. Matsuda, and T. Morikawa, "Triterpene saponin constituents from roots of Bupleurum falcatum: Hepatoprotective effects on D-galactosamine-induced cell damage," Planta Medica, vol. 81, no. S 01, pp. S1-S381, 2016.

[16] M. Sarwar and M. Salman, "Toxicity of oils formulation as a new useful tool in crop protection for insect pests control," International Journal of Chemical and Biomolecular Science, vol. 1, no. 4, pp. 297-302, 2015.

[17] K. Izakmehri, M. Saber, A. Mehrvar, M. B. Hassanpouraghdam, and S. Vojoudi, "Lethal and sublethal effects of essential oils from Eucalyptus camaldulensis and Heracleum persicum against the adults of Callosobruchus maculatus," Journal of Insect Science, vol. 13, article no. 152, 2013.

[18] I.-K. Park, K.-S. Choi, D.-H. Kim et al., "Fumigant activity of plant essential oils and components from horseradish (Armoracia rusticana), anise (Pimpinella anisum) and garlic (Allium sativum) oils against Lycoriella ingenua (Diptera: Sciaridae)," Pest Management Science, vol. 62, no. 8, pp. 723-728, 2006.

[19] D. H. Kim and Y. J. Ahn, "Contact and fumigant activities of constituents of Foeniculum vulgare fruit against three coleopteran stored-product insects," Pest Management Science, vol. 57, no. 3, pp. 301-306, 2001.

[20] J. A. González, A. Estévezbraun, R. Estévezreyes et al., "Biological activity of secondary metabolites from Bupleurum salicifolium (Umbelliferae)," Experientia, vol. 51, no. 1, pp. 35-39, 1995.

[21] X.-Q. Li, Z.-G. He, K.-S. Bi, Z.-H. Song, and L. Xu, "Essential oil analyses of the root oils of 10 Bupleurum species from China," Journal of Essential Oil Research, vol. 19, no. 3, pp. 234-238, 2007.
[22] National Pharmacopoeia Committee, Pharmacopoeia of Peoples Republic of China, China Medical Science and Technology Press, Beijing, China, 2015.

[23] Z. L. Liu and S. H. Ho, "Bioactivity of the essential oil extracted from Evodia rutaecarpa Hook f. et Thomas against the grain storage insects, Sitophilus zeamais Motsch. and Tribolium castaneum (Herbst)," Journal of Stored Products Research, vol. 35, no. 4, pp. 317-328, 1999.

[24] M. Sakuma, "Probit analysis of preference data," Applied Entomology and Zoology, vol. 33, no. 3, pp. 339-347, 1998.

[25] H.-Y. Zhou, N.-N. Zhao, S.-S. Du et al., "Insecticidal activity of the essential oil of Lonicera japonica flower buds and its main constituent compounds against two grain storage insects," Journal of Medicinal Plants Research, vol. 6, no. 5, 2012.

[26] K. Yang, C. F. Wang, C. X. You et al., "Bioactivity of essential oil of Litsea cubeba from China and its main compounds against two stored product insects," Journal of Asia-Pacific Entomology, vol. 17, no. 3, pp. 459-466, 2014.

[27] W. S. Abbott, "A method of computing the effectiveness of an insecticide," Journal of the American Mosquito Control Association, vol. 3, no. 2, pp. 302-303, 1987.

[28] J. S. Zhang, N. N. Zhao, Q. Z. Liu et al., "Repellent constituents of essential oil of Cymbopogon distans aerial parts against two stored-product insects," Journal of Agricultural and Food Chemistry, vol. 59, no. 18, pp. 9910-9915, 2011.

[29] F. Bakkali, S. Averbeck, D. Averbeck, and M. Idaomar, "Biological effects of essential oils-a review," Food and Chemical Toxicology, vol. 46, no. 2, pp. 446-475, 2008.

[30] C. X. You, K. Yang, Y. Wu et al., "Chemical composition and insecticidal activities of the essential oil of Perilla frutescens (L.) Britt. aerial parts against two stored product insects," European Food Research and Technology, vol. 239, pp. 481-490, 2014.

[31] S. Guo, W. Zhang, J. Liang et al., "Contact and repellent activities of the essential oil from Juniperus formosana against two stored product insects," Molecules, vol. 21, no. 4, article no. 504, 2016.

[32] C. X. You, H. Y. Jiang, W. J. Zhang et al., "Contact toxicity and repellency of the main components from the essential oil of Clausena anisum-olens against two stored product insects," Journal of Insect Science, vol. 15, no. 1, 2015.

[33] V. Caprioli, G. Cimino, R. Colle, M. Gavagnin, G. Sodano, and A. Spinella, "Insect antifeedant activity and hot taste for humans of selected natural and synthetic 1,4-dialdehydes," Journal of Natural Products, vol. 50, no. 2, pp. 146-151, 1987.

[34] C.-X. You, Y. Wang, W.-J. Zhang et al., "Chemical constituents and biological activities of the Purple Perilla essential oil against Lasioderma serricorne," Industrial Crops and Products, vol. 61, pp. 331-337, 2014.

[35] A. Khani and M. Heydarian, "Fumigant and repellent properties of sesquiterpene-rich essential oil from Teucrium polium subsp. capitatum (L.)," Asian Pacific Journal of Tropical Medicine, vol. 7, no. 12, pp. 956-961, 2014. 

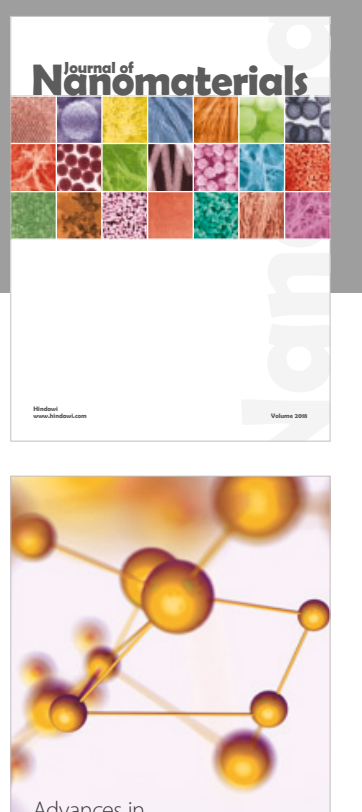

Physical Chemistry
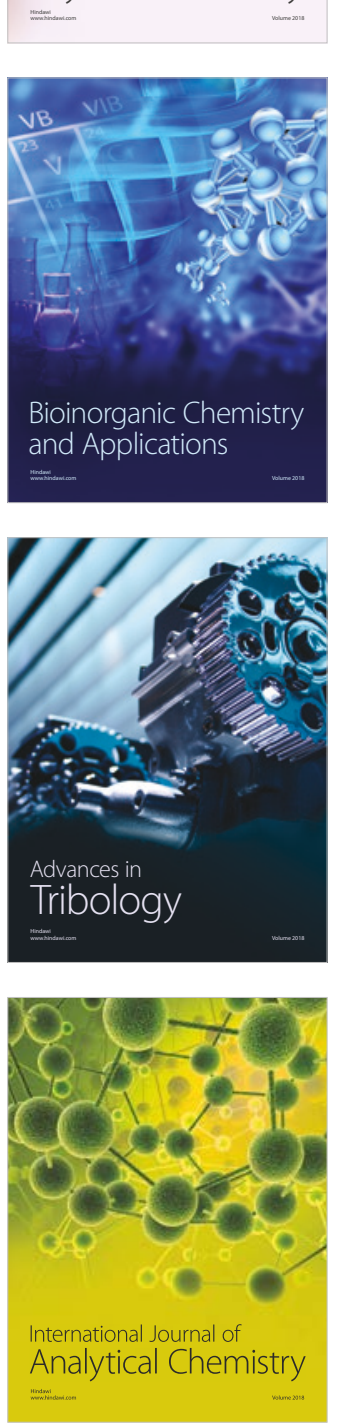

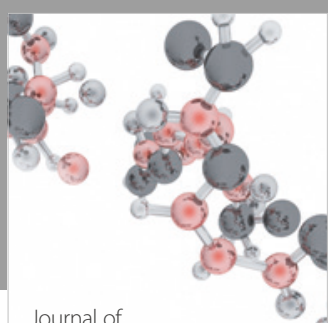

Analytical Methods

in Chemistry

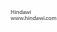

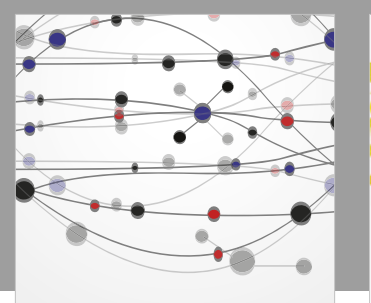

The Scientific World Journal

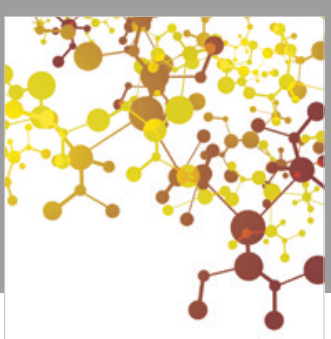

Journal of

Applied Chemistry
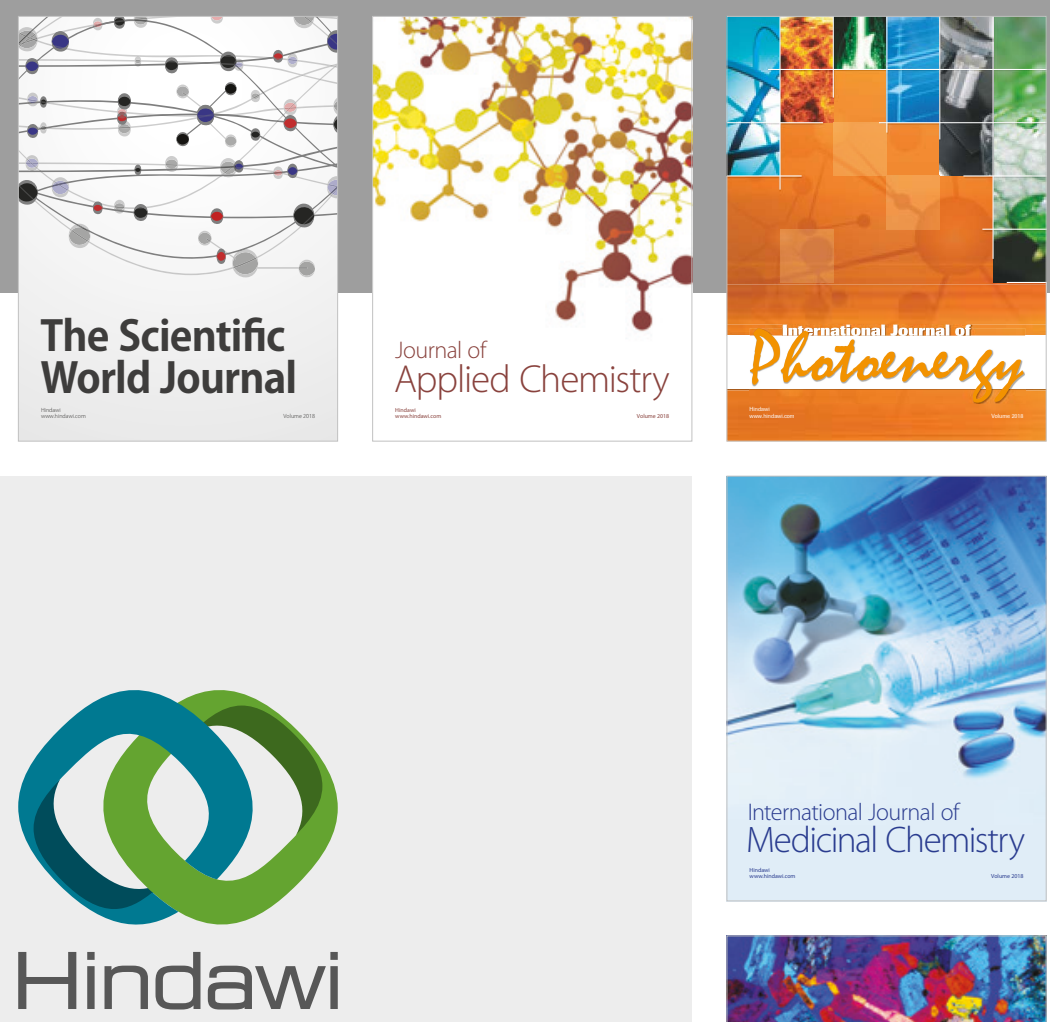

Submit your manuscripts at

www.hindawi.com
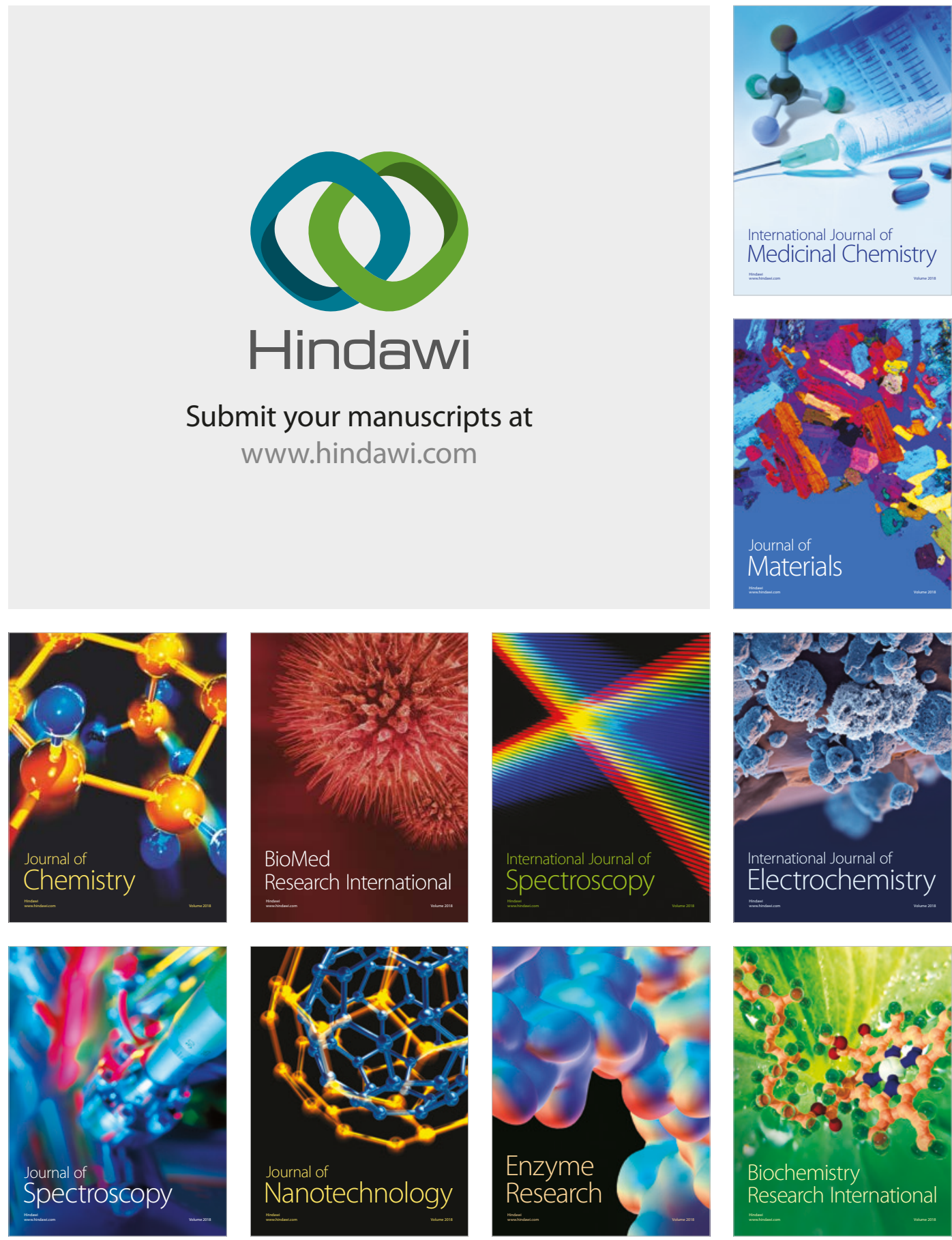
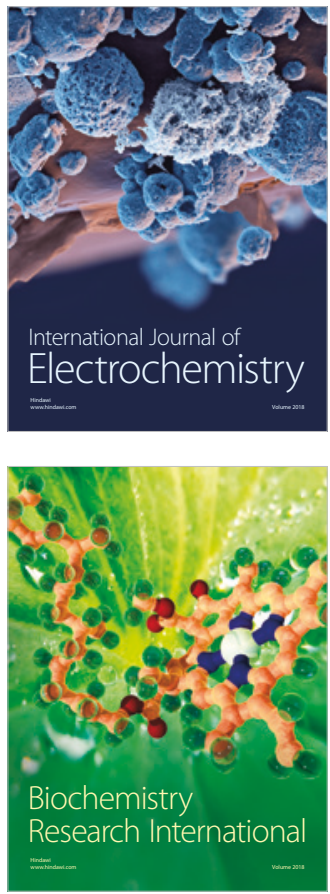